\title{
DEVELOPMENT OF NEXT-GENERATION NI-BASE SINGLE CRYSTAL SUPERALLOYS
}

\author{
Yutaka KOIZUMI, ${ }^{1}$ Toshiharu KOBAYASHI, ${ }^{1}$ Tadaharu YOKOKAWA, ${ }^{1}$ \\ ZHANG Jianxin, ${ }^{1}$ Makoto OSAWA ${ }^{1}$, Hiroshi HARADA, ${ }^{1}$ \\ Yasuhiro AOKI, ${ }^{2}$ and Mikiya ARAI ${ }^{2}$ \\ ${ }^{1}$ High Temperature Materials 21 Project, National Institute for Materials Science (NIMS) \\ 1-2-1 Sengen, Tsukuba Science City, Ibaraki 305-0047, Japan \\ ${ }^{2}$ Materials Technology Department, Aeroengine \& Space Operations, \\ Ishikawajima-Harima Heavy Industries (IHI), Japan
}

Key words: Single crystal superalloy, Phase stability, Lattice misfit, Solution strengthening, Ruthenium, Rhenium, Iridium

\begin{abstract}
Based on a fourth generation single crystal (SC) superalloy, TMS-138, we designed new SC alloys that contain higher amount of refractory elements, $\mathrm{Nb}$, $\mathrm{Ta}, \mathrm{Mo}$, or $\mathrm{Re}$, for strengthening. The Ru content was also increased to improve the phase stability. The creep strength and microstructure of these alloys were examined and compared with those of the base alloy TMS-138 and a third generation SC superalloy, CMSX-10K

As predicted by our alloy design program, TMS-162 (Mo and $\mathrm{Ru}$ addition) and TMS-173 (Re and Ru addition) exhibited excellent creep properties. Their times to $1 \%$ creep deformation at $1100^{\circ} \mathrm{C} / 137 \mathrm{MPa}$ were about 2.5 times as long as that of TMS-138 and 5 times as long as that of CMSX-10K. The temperature capability of TMS- 162 has reached a project target of $1100^{\circ} \mathrm{C}$ under stress at $137 \mathrm{MPa}$ and a creep rupture life as long as $1000 \mathrm{~h}$, which is the highest ever reported.
\end{abstract}

\section{INTRODUCTION}

Since the introduction in early 80 's[1], Ni-base single crystal superalloys have been widely used as turbine aerofoil materials in jet engines and industrial gas turbines to increase the turbine inlet gas temperatures and improve thermal efficiencies. In the latest civil aeroengines, for instance, so-called third generation SC superalloy CMSX-10 (RR3000) has been used for uncooled intermediate-pressure blades [2] whose metal temperatures can rise above $1000^{\circ} \mathrm{C}$ at takeoff. This alloy contains up to $6 \mathrm{wt} \%$ rhenium $(\mathrm{Re})$ to improve the creep strength. However, the total amount of strengthening elements in $3 \mathrm{rd}$ generation superalloys has been beyond the solubility limit. Consequently, after long-term exposure at high temperatures, significant amounts of detrimental phases, so-called topologically close-packed (TCP) phases containing high Re and other strengthening elements, form to reduce the creep strengths. This limits the actual durability of the components. To avoid this problem, new SC superalloys to be classified as 4 th generation SC alloys are being developed in the world [3].

In the Japanese government funded project, "High Temperature Materials 21", conducted by NIMS, June 1999 March 2008, we have been developing new SC superalloys with superior creep strengths as well as microstructural stabilities. The target temperature capability is $1100^{\circ} \mathrm{C}$ under stress at $137 \mathrm{MPa}$ and creep rupture times as long as $1000 \mathrm{~h}$. We had reached $1083^{\circ} \mathrm{C}$ with a fourth generation SC alloy, TMS-138 [4, 5], which is now being tested for use in a new jet engine to be made in Japan. However, the target had not been achieved yet.

In this study, we are developing next generation SC superalloys that meet the target for achieving new aeroengines and advanced industrial gas turbines with very high thermal efficiencies.

\section{ALLOY DESIGN}

New SC superalloys were designed using our fourth generation SC superalloy, TMS-138, as a base alloy. According to the calculations by the NIMS Alloy Design computer Program (NIMS-ADP) [6], each one of the refractory elements, $\mathrm{Nb}, \mathrm{Ta}$, Mo or Re, was added by 0.7 at $\%$ to TMS- 138 . The amount of addition, $0.7 \mathrm{at} \%$, was decided so that the heat treatment window is larger than $15^{\circ} \mathrm{C}$, and the alloy density is smaller than 9.2. Other materials parameters including phase compositions, lattice misfit, creep strengths, and so on, were also calculated and taken into consideration.

The refractory element additions, however, normally decrease the phase stability, and make the alloy TCP-prone. To suppress the possible TCP formation, all the platinum group 
Table 1 Chemical compositions (wt\%,bal.Ni) of single crystal superalloys examined in this study. Heat treatment windows, lattice misfit values, and creep rupture lives calculated by NIMS Alloy Design Program are also shown.

\begin{tabular}{|c|c|c|c|c|c|c|c|c|c|c|c|c|c|c|c|}
\hline Alloys & Co & $\mathrm{Cr}$ & Mo & W & $\mathrm{Al}$ & $\mathrm{Ti}$ & $\mathrm{Nb}$ & $\mathrm{Ta}$ & Hf & $\operatorname{Re}$ & Ir & $\mathrm{Ru}$ & \begin{tabular}{|l|} 
Heat \\
treatment \\
window* \\
$\left({ }^{\circ} \mathrm{C}\right)$ \\
\end{tabular} & \begin{tabular}{|l|}
$1100^{\circ} \mathrm{C}$ \\
Lattice \\
misfit* \\
$(\%)$
\end{tabular} & $\begin{array}{l}1100^{\circ} \mathrm{C}, \\
137 \mathrm{MPa} \\
\text { Creep } \\
\text { rupture } \\
\text { life* }^{*}(\mathrm{~h})\end{array}$ \\
\hline CMSX-10 & 3.0 & 2.0 & 0.4 & 5.0 & 5.7 & 0.2 & 0.1 & 8.0 & 0.03 & 6.0 & - & - & 9 & -0.11 & 220 \\
\hline TMS-75 & 12.0 & 3.0 & 2.0 & 6.0 & 6.0 & - & - & 6.0 & 0.1 & 5.0 & - & - & 60 & -0.15 & 224 \\
\hline TMS-138 & 5.9 & 2.9 & 2.9 & 5.9 & 5.9 & - & - & 5.6 & 0.1 & 4.9 & - & 2.0 & 44 & -0.20 & 399 \\
\hline TMS-139 & 5.8 & 2.9 & 2.9 & 5.8 & 5.8 & - & - & 5.5 & 0.1 & 4.9 & 3.0 & - & 54 & -0.19 & 399 \\
\hline TMS-138NbRu & 5.6 & 2.8 & 2.8 & 5.6 & 5.6 & - & 1.0 & 5.6 & 0.1 & 4.7 & - & 5.0 & 26 & -0.09 & 302 \\
\hline TMS-138TaRu & 5.6 & 2.8 & 2.8 & 5.6 & 5.6 & - & - & 7.9 & 0.1 & 4.7 & - & 5.0 & 18 & -0.04 & 453 \\
\hline $\begin{array}{l}\text { TMS-138ReRu } \\
\text { (TMS-173) }\end{array}$ & 5.6 & 2.8 & 2.8 & 5.6 & 5.6 & - & - & 5.6 & 0.1 & 6.9 & - & 5.0 & 45 & -0.27 & 1137 \\
\hline $\begin{array}{l}\text { TMS-138MoRu } \\
\text { (TMS-162) }\end{array}$ & 5.8 & 2.9 & 3.9 & 5.8 & 5.8 & - & - & 5.6 & 0.1 & 4.9 & - & 6.0 & 35 & -0.31 & 959 \\
\hline
\end{tabular}

Table 2 Heat treatment conditions.

\begin{tabular}{lll}
\hline Alloys & Solution treatment & Aging treatment \\
\hline CMSX-10K & $1316^{\circ} \mathrm{C}, 1 \mathrm{~h} \rightarrow 1329^{\circ} \mathrm{C}, 2 \mathrm{~h} \rightarrow 1335^{\circ} \mathrm{C}, 2 \mathrm{~h} \rightarrow 1340^{\circ} \mathrm{C}, 2 \mathrm{~h}$ & $1152^{\circ} \mathrm{C}, 6 \mathrm{hAC}, 871^{\circ} \mathrm{C}, 24 \mathrm{hAC}, 760^{\circ} \mathrm{C}, 30 \mathrm{hAC}$ \\
& $\rightarrow 1346^{\circ} \mathrm{C}, 2 \mathrm{~h} \rightarrow 1352^{\circ} \mathrm{C}, 3 \mathrm{~h} \rightarrow 1357^{\circ} \mathrm{C}, 3 \mathrm{~h}$ & \\
& $\rightarrow 1360^{\circ} \mathrm{C}, 5 \mathrm{~h} \rightarrow 1363^{\circ} \mathrm{C}, 10 \mathrm{~h} \rightarrow 1365^{\circ} \mathrm{C}, 15 \mathrm{hAC}$ & \\
TMS-75 & $1300^{\circ} \mathrm{C}, 1 \mathrm{~h} \rightarrow 1320^{\circ} \mathrm{C}, 5 \mathrm{hAC}$ & $1100^{\circ} \mathrm{C}, 4 \mathrm{hAC}, 870^{\circ} \mathrm{C}, 20 \mathrm{hAC}$ \\
TMS-138 & $1300^{\circ} \mathrm{C}, 1 \mathrm{~h} \rightarrow 1340^{\circ} \mathrm{C}, 5 \mathrm{hAC}$ & $1100^{\circ} \mathrm{C}, 4 \mathrm{hAC}, 870^{\circ} \mathrm{C}, 20 \mathrm{hAC}$ \\
TMS-139 & $1300^{\circ} \mathrm{C}, 1 \mathrm{~h} \rightarrow 1340^{\circ} \mathrm{C}, 5 \mathrm{hAC}$ & $1150^{\circ} \mathrm{C}, 4 \mathrm{hAC}, 870^{\circ} \mathrm{C}, 20 \mathrm{hAC}$ \\
TMS-138NbRu & $1280^{\circ} \mathrm{C}, 1 \mathrm{~h} \rightarrow 1310^{\circ} \mathrm{C}, 5 \mathrm{hAC}$ & $1100^{\circ} \mathrm{C}, 4 \mathrm{hAC}, 870^{\circ} \mathrm{C}, 20 \mathrm{hAC}$ \\
TMS-138TaRu & $1300^{\circ} \mathrm{C}, 1 \mathrm{~h} \rightarrow 1330^{\circ} \mathrm{C}, 5 \mathrm{hAC}$ & $1100^{\circ} \mathrm{C}, 4 \mathrm{hAC}, 870^{\circ} \mathrm{C}, 20 \mathrm{hAC}$ \\
TMS-138ReRu & $1300^{\circ} \mathrm{C}, 1 \mathrm{~h} \rightarrow 1330^{\circ} \mathrm{C}, 5 \mathrm{hAC}$ & $1100^{\circ} \mathrm{C}, 4 \mathrm{hAC}, 870^{\circ} \mathrm{C}, 20 \mathrm{hAC}$ \\
TMS-138MoRu & $1300^{\circ} \mathrm{C}, 1 \mathrm{~h} \rightarrow 1330^{\circ} \mathrm{C}, 5 \mathrm{hAC}$ & $1100^{\circ} \mathrm{C}, 4 \mathrm{hAC}, 870^{\circ} \mathrm{C}, 20 \mathrm{hAC}$ \\
\hline
\end{tabular}

metal additions were found to be effective, and, for the present work, ruthenium $(\mathrm{Ru})$ was added. The alloy compositions thus designed are presented in Table 1 with those of alloys CMSX-10K, TMS-75, TMS-138 and TMS-139. TMS-139 is a 4 th generation $\mathrm{SC}$ alloy with Ir addition instead of $\mathrm{Ru}$ as a microstructure stabilizer [4].

As Mo and Re partition more to the $\gamma$ phase rather than the $\gamma^{\prime}$ phase independent of $\mathrm{Ru}$ addition [7], and the atomic volume of these elements are larger than that of $\mathrm{Ni}$, the addition of Mo or Re changes the lattice misfit towards a larger negative, as shown in the Table 1. On the other hand, $\mathrm{Nb}$ and Ta partition more to $\gamma^{\prime}$ phase and change the lattice misfit towards positive direction. Here, the lattice misfit, $\delta$, is expressed as, $\delta=\left(a \gamma^{\prime}\right.$ a $\gamma) /$ a . A larger negative lattice misfit is known to enhance rafting and the formation of a finer interfacial misfit dislocation network; both improve the alloy creep strength [5].

\section{EXPERIMENTAL PROCEDURE}

$\mathrm{SC}$ bars of $10 \mathrm{~mm}$ diameter and $130 \mathrm{~mm}$ length of the designed alloys, the base alloy (TMS-138), TMS-75, TMS-139, and CMSX-10K were cast in a NIMS directional solidification (DS) furnace with $2 \mathrm{kgs}$ of the remeltbars. The mold withdrawal rate, which corresponds to the solidification rate, was $200 \mathrm{~mm} / \mathrm{h}$ for all.

The heat treatment conditions of the newly designed alloys were selected by microstructure examination after heating small slices of the $\mathrm{SC}$ samples at various temperatures ranging from 1280 to $1360^{\circ} \mathrm{C}$ for $2 \mathrm{~h}$. The solution treatment windows of the designed alloys were found to be as large as the predictions. For instance, $15^{\circ} \mathrm{C}$ with TMS-138TaRu is the smallest; while, $40{ }^{\circ} \mathrm{C}$ with TMS-138ReRu(173) is the largest.

The actual heat treatment conditions thus determined are shown in Table 2. The heat treatment of the creep specimens was performed in argon (Ar) gas-sealed quartz tubes. After $1 \mathrm{~h}$ heating at 1280 or $1300^{\circ} \mathrm{C}$, the samples were heated up and held at the solution temperatures for $5 \mathrm{~h}$, followed by air-cooling. Two-step aging treatments were performed, first $1100^{\circ} \mathrm{C}$ for $4 \mathrm{~h}$, followed by air-cooling, and second at $870^{\circ} \mathrm{C}$ for $20 \mathrm{~h}$, followed by air-cooling. The microstructures thus 

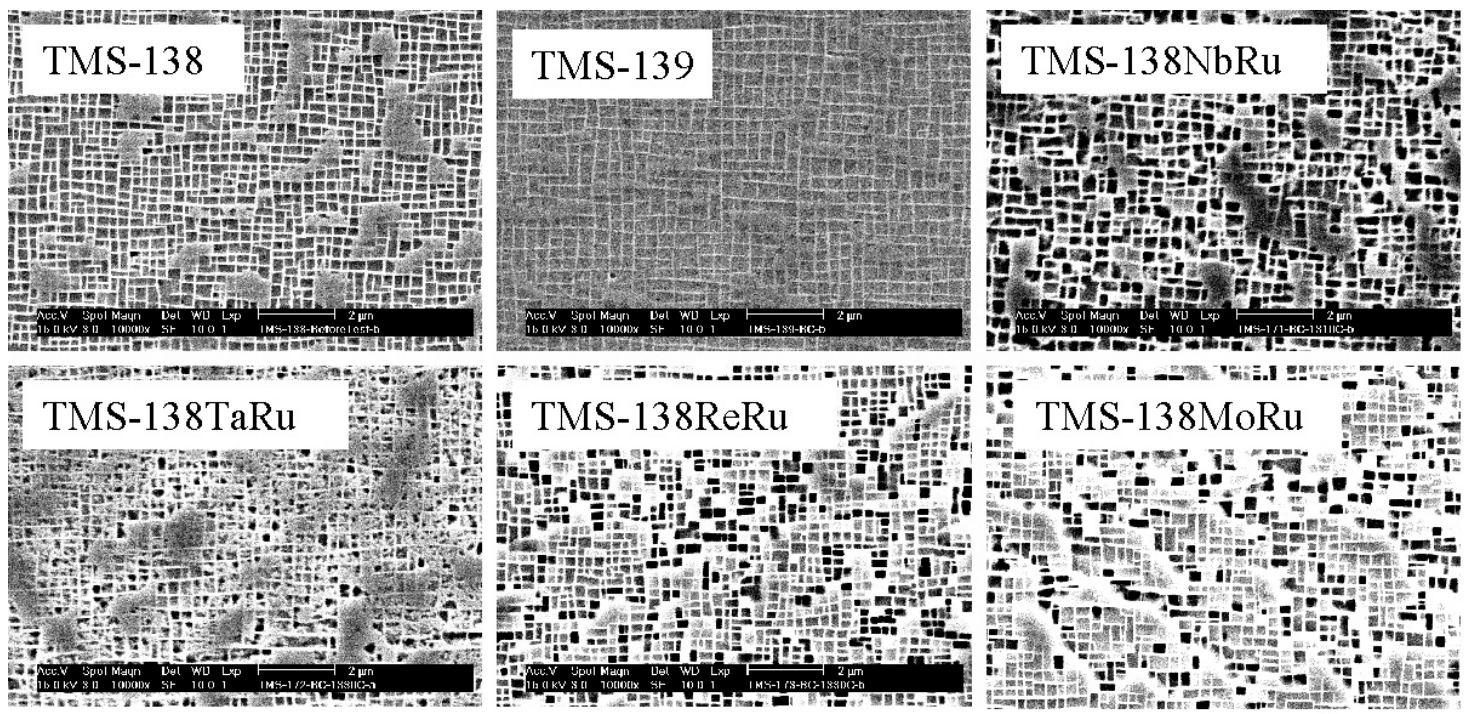

$2 \mu \mathrm{m}$

Fig. 1. Micrographs of the heat treated samples.

obtained in the newly designed alloys are shown in Fig.1. Very well aligned $\gamma / \gamma^{\prime}$ coherent structures were observed in all the alloys.

From the fully heat-treated SC bars of longitudinal axes within 10 degrees of the $<001>$ direction, cylindrical creep specimens of $4 \mathrm{~mm}$ in diameter and $20 \mathrm{~mm}$ in length as gage part were machined out and carefully finished by grinding. For TMS-138, -139 and CMSX-10K, proper heat treatments were performed before machining creep specimens to the same shape.

Creep tests were carried out mainly at $1100^{\circ} \mathrm{C} / 137 \mathrm{MPa}$, $1000^{\circ} \mathrm{C} / 245 \mathrm{MPa}$ and $800^{\circ} \mathrm{C} / 735 \mathrm{MPa}$. At 1000 and $1100^{\circ} \mathrm{C}$, a non-contact strain-measuring device developed by the authors and their collaborators was used to obtain precise creep curves; while, at lower temperatures traditional extensometer was used. Microstructures in as heat treated and creep ruptured samples were examined in a Scanning Electron Microscope (SEM) and a 200kV Transmission Electron Microscope (TEM).

\section{RESULTS AND DISCUSSION}

\section{Creep Property}

Creep curves obtained at $1100^{\circ} \mathrm{C} / 137 \mathrm{MPa}$ are presented in Fig. 2. It is clearly shown that the newly designed alloys, TMS-138ReRu(173) and $-138 \mathrm{MoRu}(162)$, have the longest creep rupture lives, which are about 3 times as long as that of CMSX-10K and 2.5 times as long as that of TMS-138. When a comparison is made in time to the $1 \%$ creep, the advantage is even more significant; the time is about 5 times as long as that of CMSX-10K and 2.5 times as long as that of TMS-138 and TMS-139.

The corresponding creep rate vs. time curves of the three

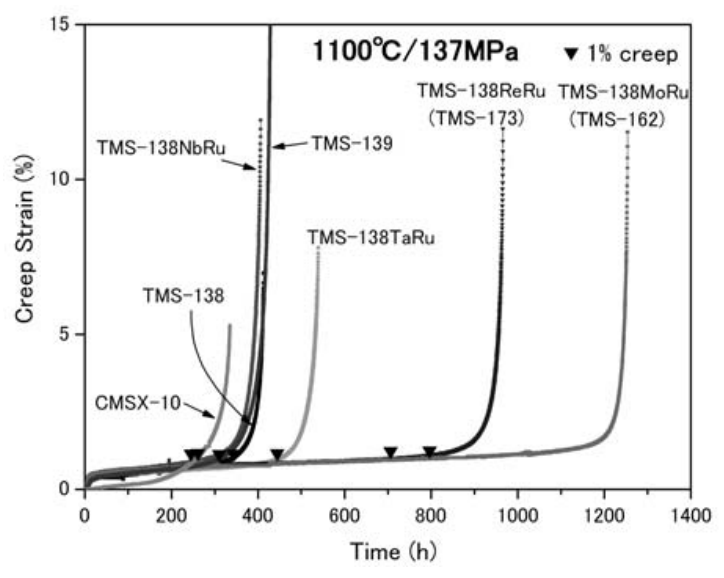

Fig. 2. Creep strain vs. time curves at $1100^{\circ} \mathrm{C} / 137 \mathrm{MPa}$.

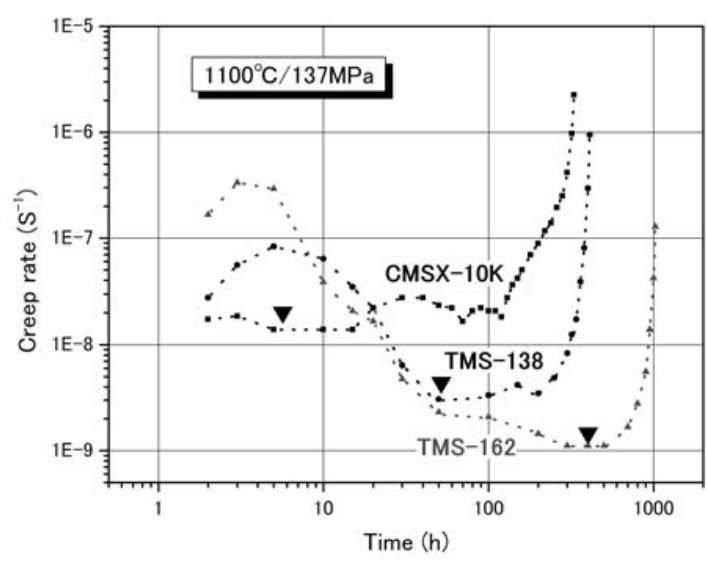

Fig.3. Creep rate-time curves of three alloys of CMSX-10K,

TMS-138, and TMS- 162 at $1100^{\circ} \mathrm{C} / 137 \mathrm{MPa}$. 
typical alloys are presented in Fig.3. This figure clearly shows that the minimum creep rate becomes smaller in the order of CMSX-10K, TMS-138, and TMS-138MoRu (162), while the time to reach the minimum creep rate is the shortest with CMSX-10 (about 3\% of creep life) and the longest with TMS-138MoRu (40\%). Also, interestingly, the initial creep rate is the largest with TMS-138MoRu (162), but the creep rate decreases with time and reaches the lowest rate, exhibiting the longest creep life among the three alloys. TMS-138 has the same tendency, although not as significant as that of TMS-138MoRu.

This unique change in the creep rate is due to the so-called rafting of the $\gamma / \gamma^{\prime}$ structure. The same tendency as we see in TMS-138 and TMS-138MoRu (162) has been observed in other SC superalloys, i.e., TMS-82+ (second generation SC alloy) and TMS-75 (third generation SC alloy) [8], and it has become clear that rafting is responsible for this. The rafting process causes an inter-diffusion of alloying elements around the $\gamma^{\prime}$ precipitates, which activates the self-diffusion of alloying elements and vacancy, and encourages the dislocation motion especially the climbing. Thus during rafting, the creep rate increases and decreases as the rafted structure is completed [9]. TMS-138MoRu (162) and TMS-138 seem to follow the same procedure.

The creep rupture strength of TMS-138MoRu (162) meets the "High Temperature Materials 21 Project" target, that is, $1000 \mathrm{~h}$ of rupture life at $1100^{\circ} \mathrm{C} / 137 \mathrm{MPa}$. This is the first Ni-base SC superalloy that ever reached a temperature capability of $1100^{\circ} \mathrm{C}$ under this condition.

Fig. 4 shows creep curves under $1000^{\circ} \mathrm{C} / 245 \mathrm{MPa}$ condition, which simulates the actual highest metal temperature in the latest jet engines at takeoff. Similar to the $1100^{\circ} \mathrm{C} / 137 \mathrm{MPa}$ condition, TMS- $138 \mathrm{MoRu}$ (162) exhibits highest creep strength, followed by TMS-138ReRu (173), TMS-138TaRu, and TMS- $138 \mathrm{NbRu}$, exactly in the same order as under $1100^{\circ} \mathrm{C} / 137 \mathrm{MPa}$. It can be seen, however, that the primary creep takes longer time compared with those at $1100^{\circ} \mathrm{C} / 137 \mathrm{MPa}$, due to the slower rafting kinetics. The tertiary creep also takes longer time presumably due to the work hardening effect being more effective in this condition than under higher temperatures.

Under $800^{\circ} \mathrm{C} / 735 \mathrm{MPa}$ creep condition which simulates a blade root part, all the newly designed alloys, especially TMS-138ReRu (173), have superior creep strengths whereas the fourth generation SC alloy TMS-138 shows about $10 \%$ initial creep followed by a fast secondary and tertiary creep deformation to rupture, as shown in Fig.5. This shows that solid solution strengthening by $\mathrm{Ru}$ is very effective at this lower temperature range.

In Fig.6, creep strengths of TMS-138MoRu (162) and

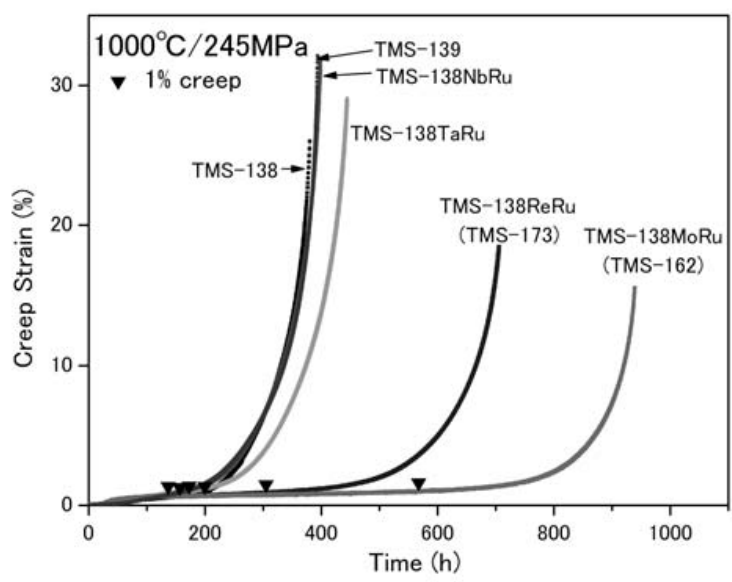

Fig. 4. Creep strain vs. time curves at $1000^{\circ} \mathrm{C} / 245 \mathrm{MPa}$.

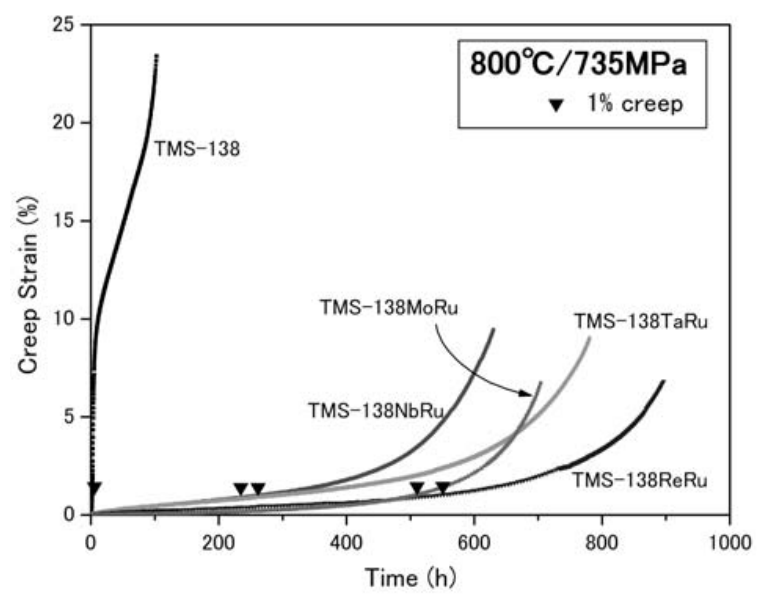

Fig.5. Creep strain vs. time curves at $800^{\circ} \mathrm{C} / 735 \mathrm{MPa}$.

TMS-138ReRu (173) are compared with those of typical SC superalloys with time to $1 \%$ creep strain. It is shown that the newly designed alloys have superior creep strength over the commercial alloys in the whole stress and temperature range, especially at lower-stress/higher-temperature and higherstress/lower- temperature conditions.

A comparison in the rupture life is presented in Fig.7. TMS-138MoRu (162) and TMS-138ReRu (173) again have excellent strength though the strength is close to CMSX-10K at intermediate-stress/intermediate-temperature range, e.g., $392 \mathrm{MPa} / 900-950^{\circ} \mathrm{C}$. In this temperature range, some TCP formation is observed in the dendritic core area in the creep ruptured samples. 


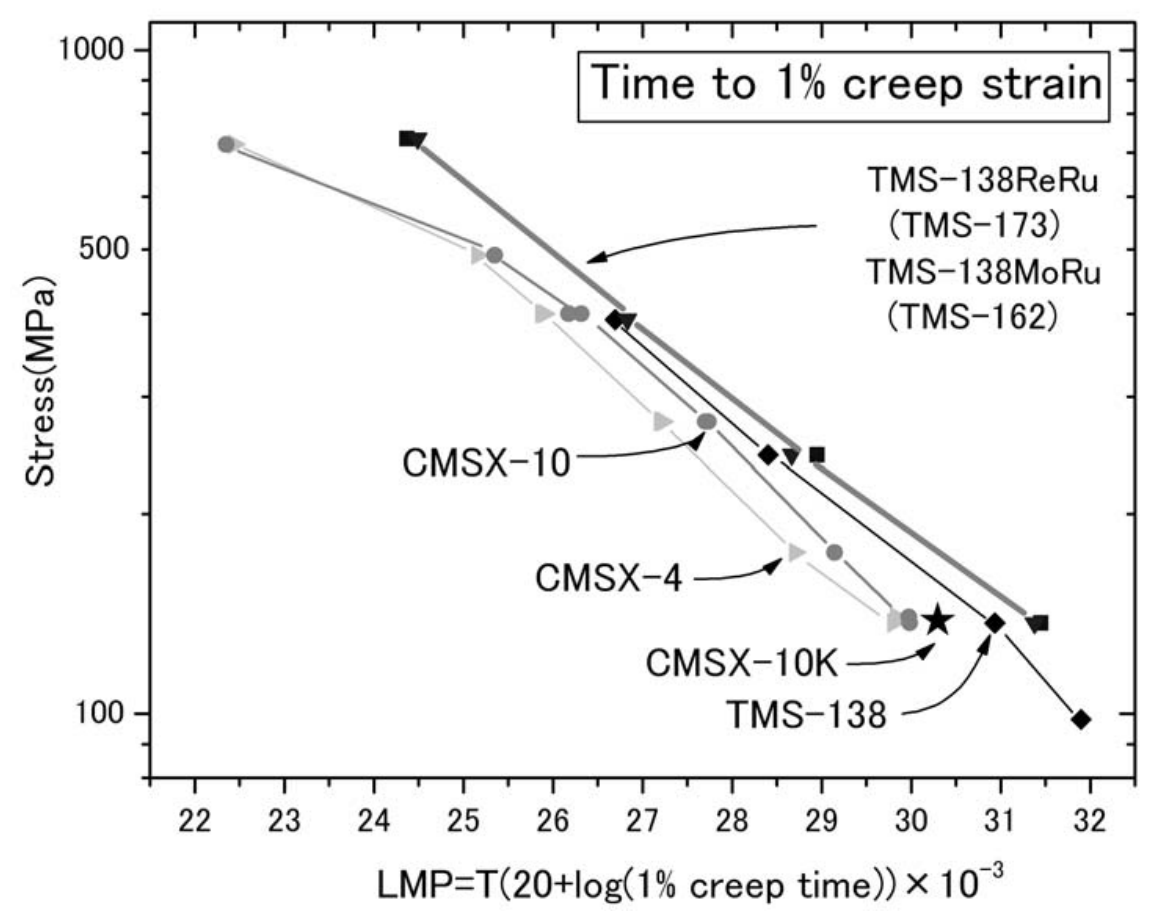

Fig. 6. Larson-Miller curves in time to $1 \%$ creep strain.

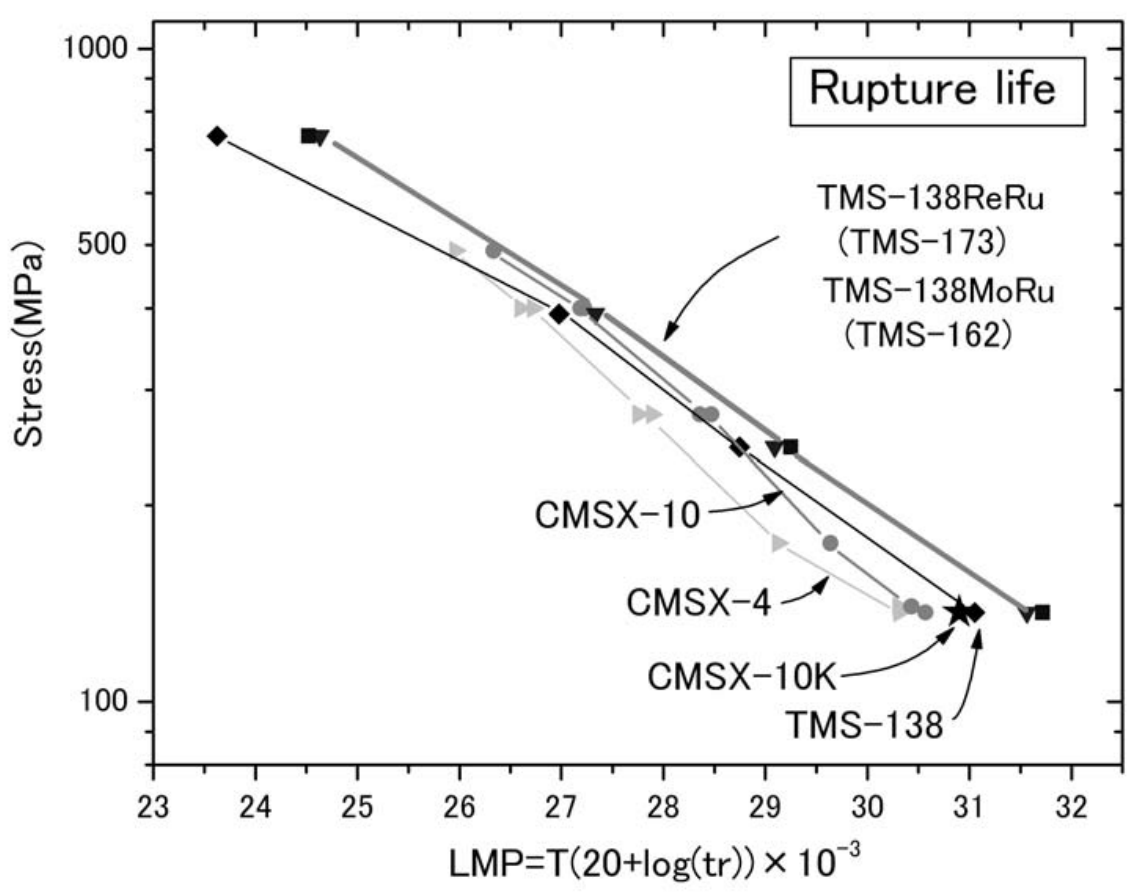

Fig. 7. Larson-Miller curves in rupture life. 


\section{Microstructure analysis}

SEM micrographs observed in the specimens ruptured at $1100^{\circ} \mathrm{C} / 137 \mathrm{MPa}$ are presented in Fig.8. In all the microstructures, rafted structures are visible but more or less deformed by dislocation cutting during the tertiary creep. The microstructures were thermodynamically very stable at this temperature and TCP phases were rather difficult to find.

TEM micrographs of CMSX-10K, TMS-138, and TMS-138MoRu (162) samples creep-ruptured at $1100^{\circ} \mathrm{C} /$ 137MPa are shown in Fig.9. The observations were made at about $6 \mathrm{~mm}$ distance from the fractured surface, where little effect of necking caused by tertiary creep deformation is expected and, consequently, the rafted structure built up during secondary creep is well preserved.

By the observation, we found dislocation network generated on the rafted $\gamma / \gamma^{\prime}$ interface perpendicular to the stress axis near $<001>$. The dislocation network is also preserved during cooling after the creep rupture because of its nature; the dislocations restrain each other and also require climbing to move. The dislocation network becomes finer in the order of CMSX-10K, TMS-138, and TMS-138MoRu (162), where TMS-162 is the finest. When the lattice misfit becomes larger in the negative, the interfacial dislocation network becomes finer to relieve the coherency strain. The difference in the dislocation spacing observed in Fig.9 is attributed to the difference in the lattice misfit mainly due to the difference in the Mo content as designed.

The minimum creep rate at $1100^{\circ} \mathrm{C} / 137 \mathrm{MPa}$ is plotted against the mean dislocation spacing in Fig.10. There is a linear relationship between the minimum creep rate and the dislocation spacing. As the Mo amount increases and the $\gamma / \gamma^{\prime}$ interfacial dislocation network becomes finer, the minimum creep rate decreases greatly. The same relationship has been reported in previous papers by some of the authors of the present paper and their coworkers.

During creep at a higher temperature and a lower stress condition such as $1100^{\circ} \mathrm{C} / 137 \mathrm{MPa}$, the rafted structure is ideally built up, and the $\gamma$ channel parallel to the stress axis almost disappears; as a result, dislocation climbing along the longitudinal direction becomes very difficult. This is the reason why the creep rate decreases when the rafted structure is building up. In this situation, as an alternative way for the gliding dislocations to move, they start cutting into the $\gamma^{\prime}$ phase as superdislocations [10]. Here, the $\gamma / \gamma^{\prime}$ interfacial dislocation network effectively prevents the dislocation cutting into $\gamma^{\prime}$ because the gliding dislocations must pass through the dislocation network. The stress, $\tau$, needed for a dislocation to bow out of the network is expressed as, $\tau=\alpha \mathrm{Gb} / \mathrm{R}$, where $\alpha$ is a constant value, $G$ is the shear stress, $b$ is the Burger's vector, and $\mathrm{R}$ is the radius of the dislocation bowing out [11]. As the network becomes finer, the $\mathrm{R}$ becomes smaller, and $\tau$ becomes larger. This means that a higher shear stress is needed for the dislocation to pass through a finer dislocation network, which resulted in the relationship shown in Fig. 10. The remarkable creep strength of TMS-138MoRu (162) and TMS-138ReRu (173) is thus attributed to this fine dislocation network generated on the rafted $\gamma / \gamma^{\prime}$ interfaces. Creep deformation mechanisms described above are discussed more in details by Zhang, et. al,[12] in this same volume.
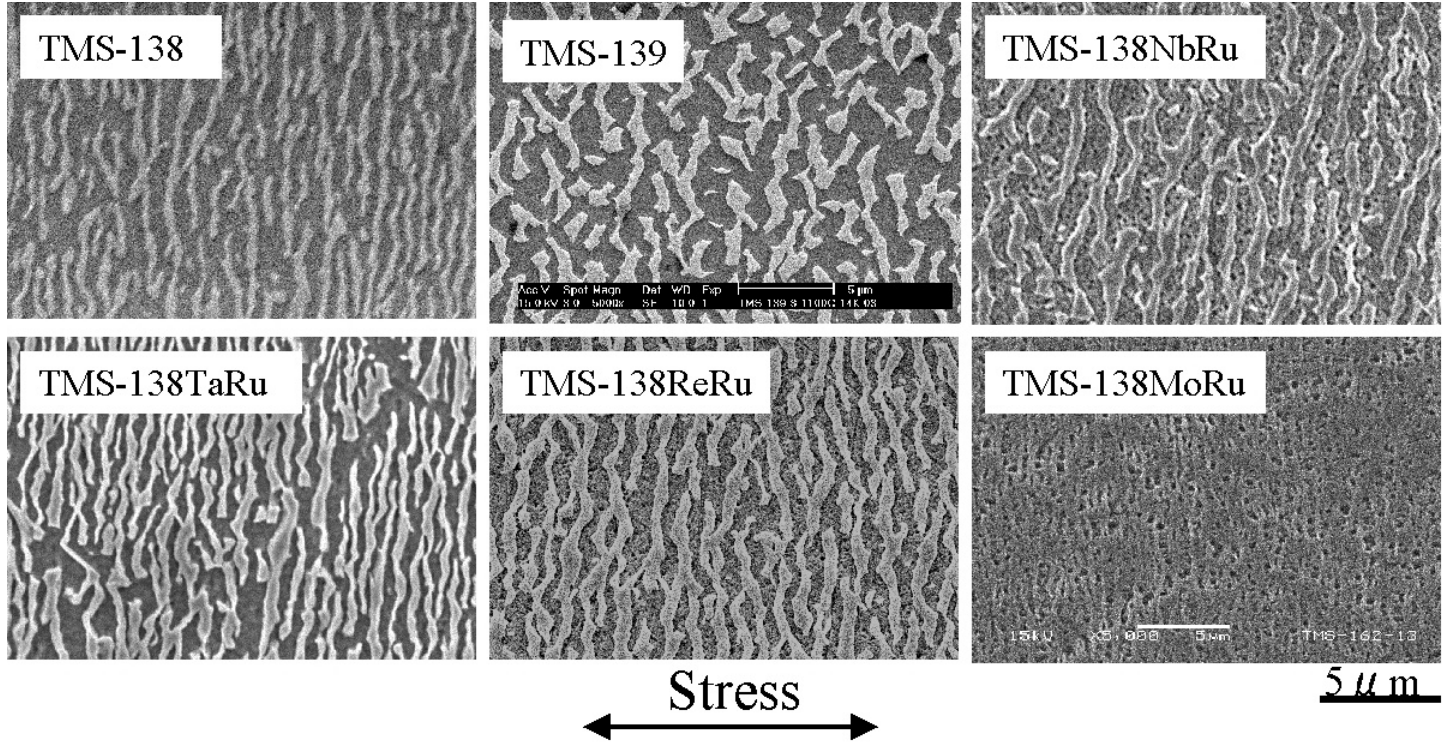

$5 \mu \mathrm{m}$

Fig.8. SEM micrographs of creep ruptured samples at $1100^{\circ} \mathrm{C} / 137 \mathrm{MPa}$. 

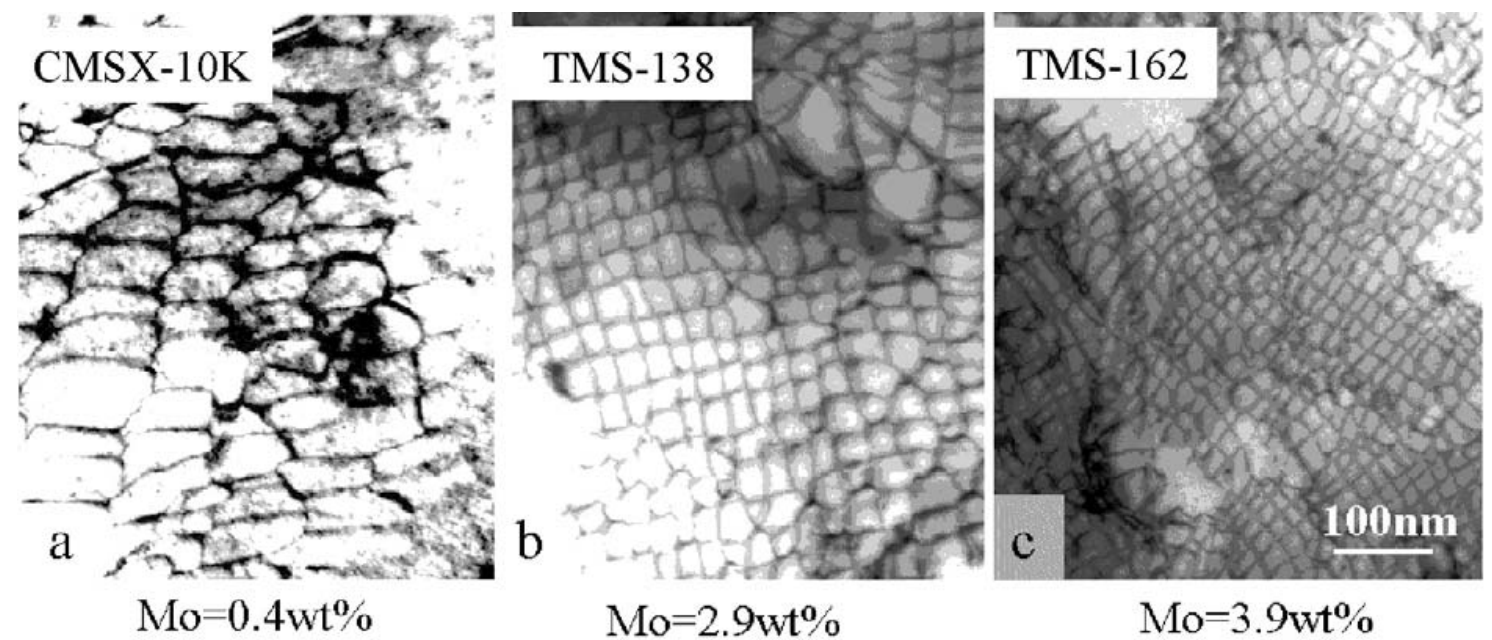

Fig.9. Transmission electron micrographs of the creep ruptured alloy of CMSX-10(a),TMS-138(b) and TMS-162(c),showing the difference in the interface dislocation networks among three ruptured alloys.

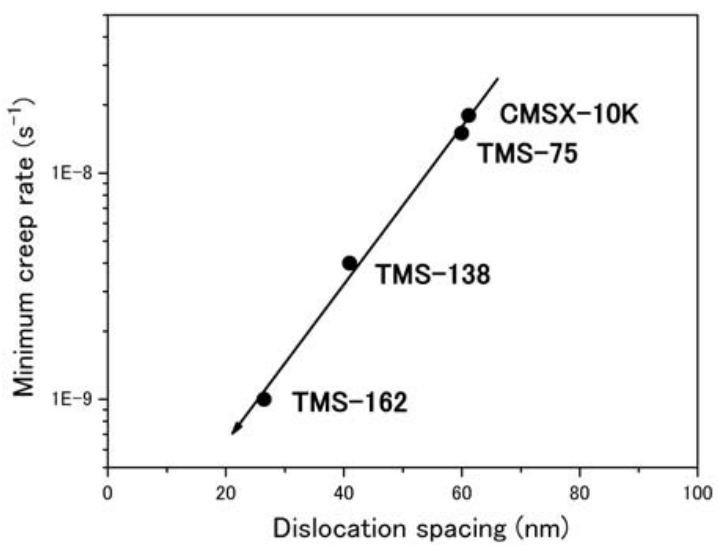

Fig. 10 Minimum creep rates of CMSX-10K, TMS-138, and TMS-162 as a function of their interfacial dislocation spacing.

\section{Long term stability and environmental properties}

Microstructure stability of TMS-138MoRu (162) and TMS-138ReRu (173) was examined at temperatures ranging from $900^{\circ} \mathrm{C}$ to $1200^{\circ} \mathrm{C}$ for up to $1000 \mathrm{~h}$. It was found that the microstructures of the alloys are stable at higher temperatures; no TCP phases were observed at $1200^{\circ} \mathrm{C}$ and very few observed at $1100^{\circ} \mathrm{C}$. However, at $1000^{\circ} \mathrm{C}$ and $900^{\circ} \mathrm{C}$, TCP phase started to precipitate in the dendritic core area at times less than $100 \mathrm{~h}$. The amount of TCP phase was larger in TMS-138ReRu (173) with $6.9 \mathrm{wt} \%$ Re compared with TMS-138MoRu (162) with $4.9 \mathrm{wt} \%$ Re. A longer solution treatment, instead of the $5 \mathrm{~h}$ simple solution treatment performed in this study, will minimize the solidification segregation of Re and, consequently, the TCP formation, and further improve the creep strengths in the $900-1000^{\circ} \mathrm{C}$ temperature range.

Oxidation resistance of TMS-138MoRu (162) and TMS-138ReRu (173) was studied under isothermal heating condition for up to $1000 \mathrm{~h}$. It has been shown that these alloys, especially TMS- $138 \mathrm{MoRu}$ (162) containing the highest $\mathrm{Ru}$ content, $6.0 \mathrm{wt} \%$, are less oxidation resistant compared with the base alloy TMS-138. Although it depended on the temperature, the weight gain or loss is about twice as large as those with 2 nd, 3 rd and 4 th generation SC alloys including TMS-82+, TMS-75 and TMS-138. For practical use of TMS-138MoRu (162) and TMS-138ReRu (173), oxidation protection by reliable coating systems is essential.

\section{Possibilities for future developments}

Fig.11 shows a very good agreement between calculated and experimental creep rupture lives. The prediction equation does not include the effect of $\mathrm{Ru}$, and yet a good agreement is obtained. This confirms that $\mathrm{Ru}$ is not a strengthening element at this condition, but a phase stabilizing element.

Fig.12 summarizes the alloy design in this paper. Based on TMS-138, Mo and Re additions change lattice misfit toward larger in negative, which improves creep strength. $\mathrm{Nb}$ and $\mathrm{Ta}$ additions, on the other hand, tend to bring lattice misfit closer to zero. In this case, although $\gamma^{\prime}$ phase is solid solution strengthened, this benefit is almost canceled out by the lattice misfit shift in the wrong direction. If the lattice misfit becomes smaller in negative, dislocation network becomes coarser and creep deformation by dislocation cutting becomes easier. 


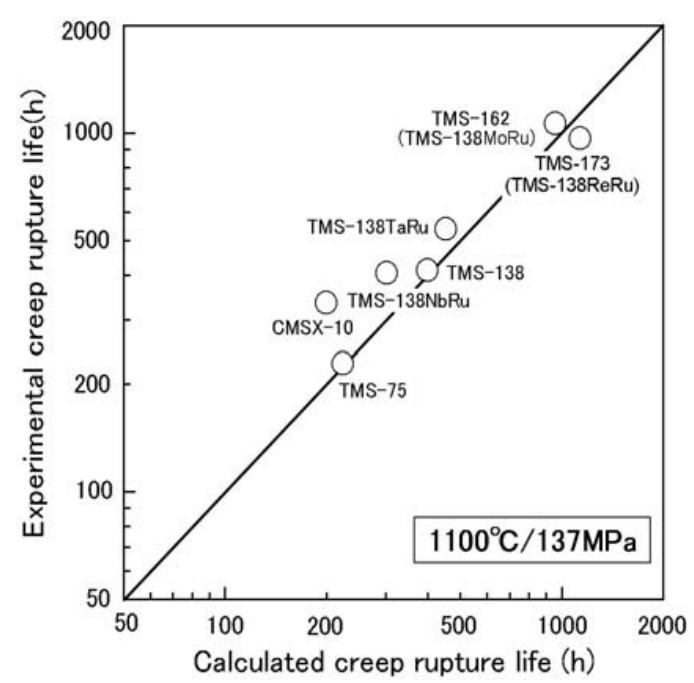

Fig. 11. Relationship between calculated and experimental creep rupture lives.

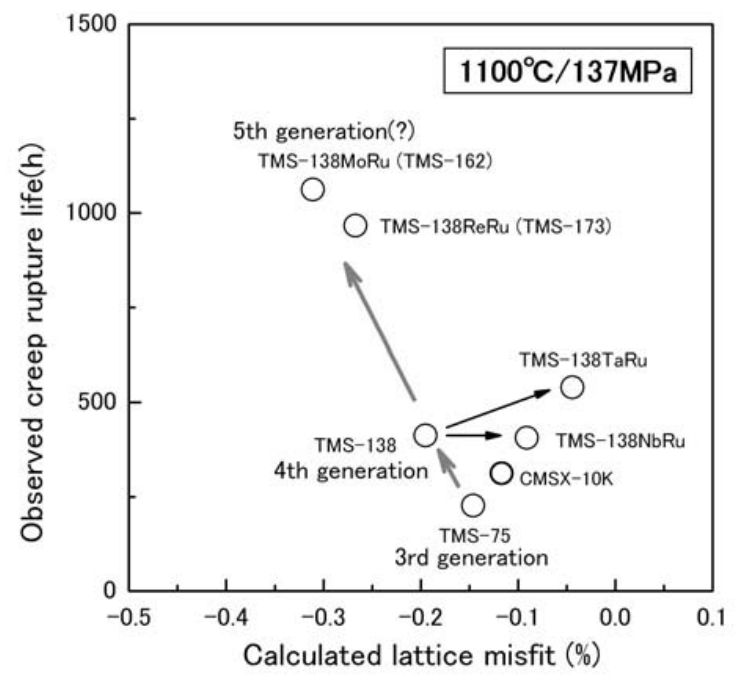

Fig. 12. Relationship between creep rupture life and lattice misfit.

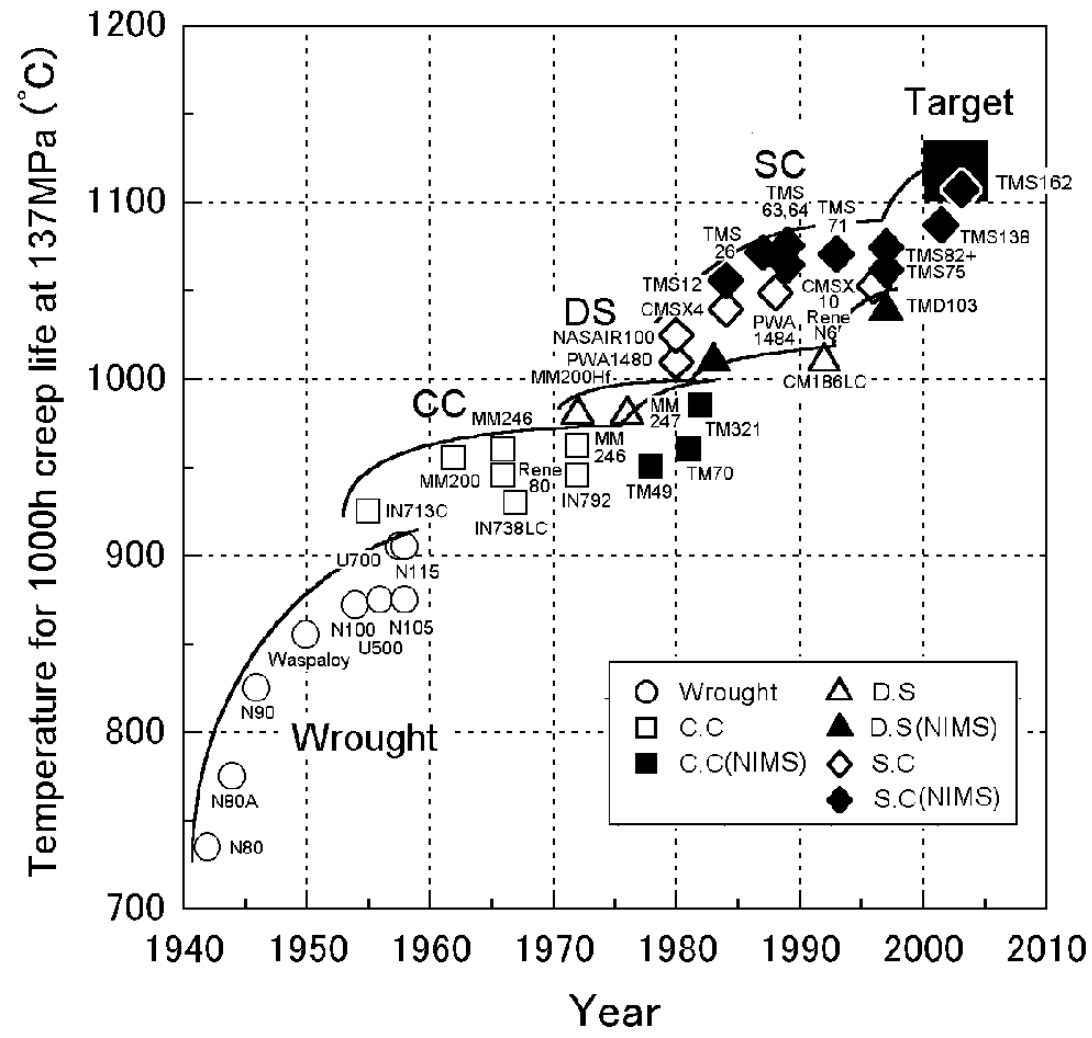

Fig. 13. History of improvement in temperature capability of Ni-base superalloys. 
Fig.13 presents a history of the improvement in the temperature capability of Ni-base superalloys. TMS-138MoRu (162) is plotted at $1105^{\circ} \mathrm{C}$, which is the highest temperature capability ever reported with SC superalloys. The alloy density was measured to be 9.04, which is similar to that of CMSX-10. In the last 24 years since the introduction of SC superalloys, e.g., PWA1480 in 1980, the temperature capability of SC superalloys has been improved by $100^{\circ} \mathrm{C}$. Further improvements beyond TMS-138MoRu(162) and TMS-138ReRu (173) are theoretically possible with the same methodology established in this work.

\section{CONCLUSIONS}

Based on a fourth generation SC superalloy TMS-138, we designed new alloys containing higher amount of refractory elements for strengthening. The Ru content was also increased to improve the phase stability. The creep strength and microstructure of the alloys were examined, and the following conclusions were reached.

(1) The developed alloy TMS-162(138MoRu) and TMS-173(138ReRu) have times to $1 \%$ creep deformation at $1100^{\circ} \mathrm{C} / 137 \mathrm{MPa}$, about 2.5 times as long as that of TMS-138 and 5 times as long as that of CMSX-10K, which is the third generation SC superalloy used in practice.

(2) There is a clear relationship between the $\gamma / \gamma^{\prime}$ interfacial dislocation network spacing and the minimum creep rate. As the spacing becomes finer, the creep rate drastically decreases.

(3) TMS-162(138MoRu) with a highest Mo content, which creates a large negative lattice misfit, has the finest interfacial dislocation network; this resulted in the longest creep life.

(4) All the high $\mathrm{Ru}(5-6 \mathrm{wt} \%)$ containing alloys showed very high creep strength at $800^{\circ} \mathrm{C} / 735 \mathrm{MPa}$, showing that solid solution strengthening by $\mathrm{Ru}$ is very effective at the lower temperature range.

(5) The temperature capability of TMS-162 (138MoRu) has reached the "High Temperature Materials 21 Project" target of a temperature capability of $1100^{\circ} \mathrm{C}$ under stress at $137 \mathrm{MPa}$ and a creep rupture life as long as $1000 \mathrm{~h}$. This temperature capability is the highest ever reported.

\section{Acknowledgements}

The authors express their sincere thanks to Mr. S. Masaki of Ishikawajima Precision Castings and Mr. M. Hosoya of Ishikawajima Harima Heavy Industries for their invaluable suggestions. Mr. H. Miyashiro, Mr. M. Kadoi, Mr. S. Nakazawa and Mr. A. Sato are also acknowledged for their support with the experiments.

\section{$\underline{\text { References }}$}

[1] M.Gell, D.N.Duhl and A.F.Giamei, Superalloys1980, pp.205-214.

[2] Erickson G.L., 1996, Superalloys 1996 (TMS AIMA, 1996) $35-43$.

[3] K.S.O'Hara, W.S.Walston, E.W.Ross, R.Darolia, U.S.Patent, 5,482,789, Jan.9,1996.

[4] Koizumi Y., T. Kobayashi, T. Yokokawa, H. Harada, Y. Aoki, M. Arai, S. Masaki, and K. Chikugo, 2001, Proc. of $2^{\text {nd }}$ International Symposium on High-Temperature Materials 2001, Tsukuba, Japan (2001) 30-31.

[5] Zhang J.X., T. Murakumo, Y. Koizumi, T. Kobayashi, H. Harada, and S. Masaki Jr., 2002, Metallurgical and Materials Transactions A, 33A, Dec. (2002) 3741-3746.

[6] H.Harada, K.Ohno, T.Yamazaki, T.Yokokawa and M.Yamazaki, Superalloys1988, Edited by S.Reichman, et.al.,The Metallurgical Society, 1988, pp.733-742.

[7] Yokokawa T., M. Osawa, K. Nishida, T. Kobayashi, Y. Koizumi, and H. Harada, Scripta Materialia 49(2003) 1041-1046.

[8] Hino T., T. Kobayashi, Y. Koizumi, H. Harada, and T. Yamagata, 2000, Superalloys 2000 (TMS AIMA,) 729-736.

[9] Mackay R.A. and L.J. Ebert, 1984, Superalloys 1984 (TMS AIMA, 1984) 135-144.

[10] Caron P. and T. Khan, 1983, Mater. Sci. Eng. 61 (1983) 173-184.

[11] Nabarro F.R.N. and H.L. de Villiers, 1995, The Physics of Creep, (Taylor and Francis, London, 1995) 85-88.

[12] J.X.Zhang, T.Murakumo, H.Harada, K.Koizumi, T.Kobayashi, to be published in the same volume, Superalloys 2004 . 
